\title{
Health-Related Quality of Life after Radical Prostatectomy and Low-Dose-Rate Brachytherapy for Localized Prostate Cancer
}

\author{
Stephen Frederic Wyler ${ }^{a}$ Daniel Stephan Engeler ${ }^{a}$ Wolfhart Seelentag ${ }^{b}$ \\ Gerhard Ries $^{b}$ Hans-Peter Schmid ${ }^{a}$ \\ Departments of a Urology and ${ }^{b}$ Radiooncology, Kantonsspital St. Gallen, St. Gallen, Switzerland
}

\section{Key Words}

Prostate cancer • Radical prostatectomy • Brachytherapy • Quality of life

\begin{abstract}
Objective: To evaluate quality of life (QOL) after radical retropubic prostatectomy (RP) and low-dose-rate brachytherapy (BT). Methods: Between 2001 and 2004, RP or BT was performed in 212 patients. QOL data were evaluated with the European Organization for Research and Treatment of Cancer QLQ-C30 version 3.0, the International Prostate Symptom Score (IPSS) and the International Index of Erectile Function-5 questionnaires. QOL data were compared. Results: RP and BT were performed in 142 and 70 patients, respectively. The mean follow-up was 24 months (5-53). The mean overall global health score for patients after RP was 78 (0-100) and after BT it was 83 (33-100), and it showed a trend in favour of BT. The follow-up lasted at most 53 months, and the period was divided into yearly categories. Patients who underwent BT showed worse global health in the first year after operation, but thereafter they showed better health. Patients who received BT showed a trend towards having lower functional-scale and symptom-scale scores in the first year after operation, and then higher scores for any subsequent year of follow-up. Only diarrhoea was temporarily worse in the second year after BT compared to RP. The mean total IPSS and $\mathrm{QOL}$ score for BT and RP patients during follow-up showed
\end{abstract}

\section{KARGER}

Fax +41613061234 E-Mail karger@karger.ch www.karger.com (c) 2009 S. Karger AG, Basel 0042-1138/09/0821-0017\$26.00/0

Accessible online at:

www.karger.com/uin no significant difference. Conclusion: Patients treated with BT or RP have similar QOL scores. QOL after BT is worse in the first year after treatment, but thereafter it is better than $\mathrm{QOL}$ after RP.

Copyright $\odot 2009$ S. Karger AG, Basel

\section{Introduction}

The widespread use of prostate-specific antigen (PSA) for the detection of prostate carcinoma has led to an increase in the number of patients who present with earlystage disease. According to age, comorbidity, clinical tumour stage, PSA and Gleason score, an individual treatment strategy is decided up by the patient and his physician [1].

Many patients are well-informed, and place importance not only on survival, but also their quality of life (QOL) after treatment [2]. Indeed, studies have indicated that patients are even prepared to choose a therapy that offers a shorter life expectancy if it is associated with a better QOL [3].

Compared to patients who receive brachytherapy (BT), those who undergo radical retropubic prostatectomy (RP) consider their disease more serious. The RP patient group believes more strongly that the treatment they choose offers the best chance of cure, whereas the BT patient group believes that the method is less invasive,

Dr. Stephen Wyler

Department of Urology, University Hospital Base

Spitalstrasse 21

CH-4031 Basel (Switzerland)

Tel. +41 61265 2525, Fax +41 61265 7690,E-Mail swyler@uhbs.ch 
has fewer side effects, is less painful and is more convenient [4].

BT is considered to be a minimally invasive treatment alternative to RP or percutaneous radiotherapy for lowrisk prostate cancers. There is a growing interest among patients and physicians in this technique and it has been recently taken into evaluation for mandatory compensation by health-care insurance schemes in Switzerland. Data on intermediate- and long-term follow-up concerning QOL after this relatively new technique are scarce. As the first institution offering BT in Switzerland (since 2001), we felt it was timely to evaluate the intermediateterm QOL of our patients.

\section{Patients and Methods}

\section{Patients}

Consecutive patients with clinically localized prostate cancer who were treated at a single institution with radical RP (from January 2002 to December 2004, $\mathrm{n}=142$ ), or low-dose-rate BT (from March 2001 to December 2004, n = 70), had been prospectively evaluated for general and oncological data (PSA value, biopsy Gleason score, clinical tumour stage, perioperative complications, pathological tumour stage and tumour grade). This database was used for contacting patients by mail. All patients were sent a set of questionnaires containing the European Organization for Research and Treatment of Cancer QLQ-C30 version 3.0 (EORTC QLQ-C30), the International Prostate Symptom Score (IPSS) and the International Index of Erectile Function-5 (IIEF-5) questionnaires.

\section{Surgical and BT Techniques}

Radical retropubic prostatectomy was performed in patients with disease that was defined clinically as being organ confined, and who had a negative computed tomogram of the pelvis and a negative bone scan. We used the standard RP technique, as described by Walsh [5]. The nerve-sparing technique was not routinely performed, but only done in select cases. Nerve sparing was only performed in preoperatively potent men with PSA $<10 \mu \mathrm{g} / \mathrm{l}$, who had unilateral cancer on biopsy and who wished to preserve potency $(n=14)$. Catheter removal was performed after 12 days if the cystogram showed an intact anastomosis.

BT was performed as monotherapy in low- or intermediaterisk patients (low risk was defined as PSA $<10 \mathrm{ng} / \mathrm{ml}$, clinical stage T1c-T2a, Gleason score $<7$; intermediate risk was either PSA $10-20 \mathrm{ng} / \mathrm{ml}$ or clinical stage T2b or Gleason score $=7$ ), as recommended by the Swiss National Health Department. Only patients with a prostate $<60 \mathrm{ml}$, a urinary flow rate $>10 \mathrm{ml} / \mathrm{s}$ and no significant residual urine were selected. Antiandrogen therapy, consisting of LH-RH analogs, was started in 11 patients with large glands preoperatively to down-size the gland or in patients who wanted to postpone the operation. Therapy was only administered once, for a duration of 3 months.

Iodine-125 seeds were implanted under general anaesthesia using a perineal template-guided loading technique under TRUS and radiologic guidance. The prescription dose was $145 \mathrm{~Gy}$, in ac- cordance with ABS recommendations [6]. Intra-operative ('real time') planning was based on the TRUS images, the seed distribution was optimized for dose homogeneity and to keep organ doses within limits (220 Gy for the urethra, and a maximum partial volume of $0.3 \mathrm{~cm}^{3}$ of the rectal wall receiving the target dose of 145 Gy). Post-operative dosimetry evaluation was based on computed tomography and magnetic resonance imaging with image fusion.

A Foley catheter was inserted at the beginning of the operation and generally removed on the day of surgery or on the first day after operation, when patients were discharged. All patients were administered tamsulosin postoperatively for a minimum of 8-12 weeks.

Data Collection and Statistical Analysis

Data were entered into an excel file and statistical analysis performed with SPSS 11.5 (SPSS Inc., Chicago, Ill., USA) statistical software package.

Differences between means of the 2 groups were assessed with the Mann-Whitney U test. The Kruskal-Wallis test was used for statistical analysis of changes during follow-up within the groups. $\mathrm{p}<0.05$ was considered statistically significant.

In order to compare similar cases, patients were grouped into age categories: $40-55$ (a1), 56-65 (a2), 66-75 (a3) and $>75$ years (a4). PSA values were grouped as 0-3.9 (p1), 4-10 (p2), 10.1-20 (p3) and $>20 \mathrm{ng} / \mathrm{ml}$ (p4). Follow-up categories were 5-12 (f1), 13-24 (f2), 25-36 (f3) and 37-53 (f4) months.

\section{Results}

$\mathrm{RP}$ was performed in 142 patients and BT was performed in 70. In patients who answered the questionnaires, the mean age (range shown in parentheses) for RP was 64 years (47-75) and for BT it was 61 years $(49-75$, $\mathrm{p} \leq 0.001)$. The mean PSA for RP was $11.3 \mathrm{ng} / \mathrm{ml}(0.3-24)$ and for BT it was $6.1 \mathrm{ng} / \mathrm{ml}(1.1-12.8, \mathrm{p} \leq 0.001)$, the mean biopsy Gleason score for RP was 6.3 (5-9) and for BT it was $5.7(4-7, \mathrm{p} \leq 0.001)$. According to clinical risk categories, for RT and BT respectively, the number of patients at low risk were 27 and 39, at intermediate risk 24 and 16 , at high risk 54 and $0.74 \%$ of RP patients and $79 \%$ of BT patients returned the questionnaires. The mean (range shown in parentheses) follow-up for RP was 20 months (5-40) and for BT it was 28 months $(8-53, \mathrm{p} \leq$ 0.001). Results were therefore categorized for follow-up length, age and PSA value.

The number of patients (total $\mathrm{n}=160$, overall response rate $75 \%$ ) for age categories was 16 for a1, 74 for a2, 69 for a3 and 1 for a4. The number of patients for PSA categories was 22 for p1, 84 for p2, 41 for $\mathrm{p} 3$ and 13 for $\mathrm{p} 4$ and for follow-up it was 41 for $\mathrm{f} 1,49$ for both $\mathrm{f} 2$ and $\mathrm{f} 3$, and 21 for $\mathrm{f} 4$. 
The mean overall global health score for patients after RP and BT showed a trend (without statistical significance) in favour of BT, with the score for RP patients being $78(0-100)$ and that for BT patients being 83 (33100).

When compared for follow-up periods f1-f4, there was a trend for BT patients to score worse in the first year after operation, but to score better for any subsequent year (without statistical significance). The results were also adjusted for patient age and PSA value by taking only the most frequent and comparable groups for analysis (i.e. a2 and $\mathrm{p} 2$ ), and no change in QOL data could be found (fig. 1).

Differences in functional scales for RP and BT patients were not significant for physical functioning, role functioning, emotional functioning and social functioning (both overall and when adjusted for follow-up within groups and between different treatment groups). The only exception was cognitive functioning at 25-36 months ( $\mathrm{p}=0.029$; table 1$)$. BT patients generally showed worse scores on functional scales in the first year after operation and better scores for the following years, compared to RP patients.

BT patients had significant changes in symptom scales over time for diarrhoea $(\mathrm{p}=0.031)$, appetite loss $(\mathrm{p}=$ 0.008 ), fatigue ( $\mathrm{p}=0.031)$, and nausea and vomiting ( $\mathrm{p}=$ 0.037 ). Differences between the 2 treatment groups were significant for diarrhoea for $13-24$ months $(\mathrm{p}=0.009)$, nausea and vomiting for 5-12 months $(\mathrm{p}=0.026)$ and dyspnoea for 25-36 months ( $\mathrm{p}=0.005$; table 2 ).

The mean total IPSS score and QOL score (IPSS 8) for BT and RP, adjusted for follow-up, showed no significant difference. The IIEF-5 sum showed a significant difference between BT and RP patients for 5-36 months of follow-up. Considering a IIEF- 5 sum of $\geq 20$ as potent, we found $50 \%$ of patients after BT for $\mathrm{f} 1$ and $\mathrm{f} 2$ to be potent and $30 \%$ of patients for $\mathrm{f} 3$ and $\mathrm{f} 4$, regardless of pre-treatment erectile function.

\section{Discussion}

For men faced with the diagnosis of prostate cancer a sometimes difficult decision-making process starts. The different curative treatment modalities, RP, BT or radiotherapy (RT), have to be evaluated carefully.

Besides the oncologic outcome, QOL is of growing importance for many patients. This issue needs to be discussed with patients when planning an individualized optimal treatment. Hall et al. [7] found that for $40 \%$ of

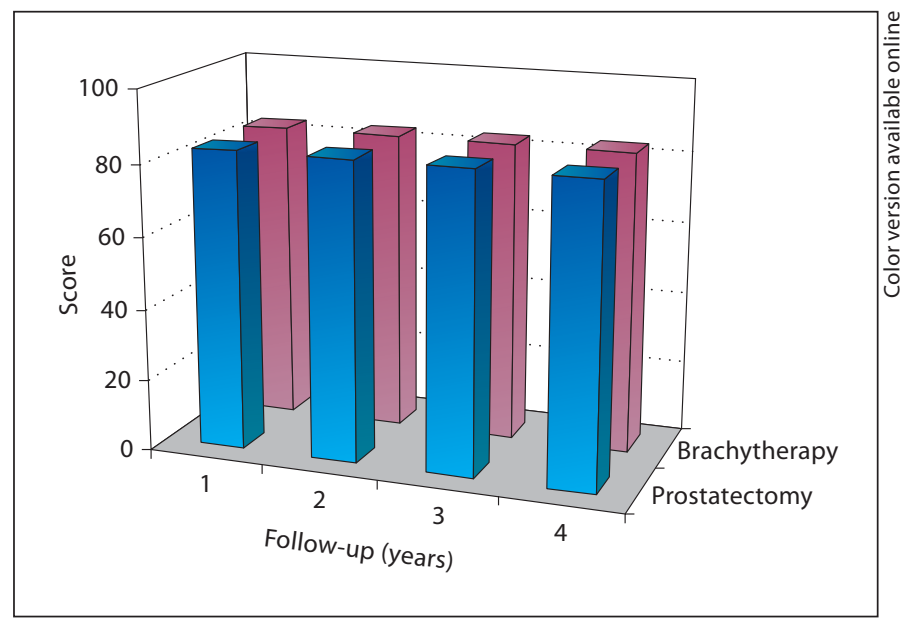

Fig. 1. Global health after RP and BT.

patients, a favourable side-effect profile is the main motivation to select BT. We therefore felt it was necessary to evaluate QOL in our patients to see whether these patient expectations are fulfilled.

At our centre we routinely offer RP, RT and BT to patients with localized prostate cancer. We have observed an increasing popularity for BT, partly because there is a perception that side-effects, and therefore QOL, are better than after surgical management. BT is considered a minimally invasive treatment option for patients with localized prostate cancer and most studies comparing different treatment modalities have focussed on acute and shortterm effects on QOL [8-10]. Although our study also evaluates intermediate-term outcome after therapy, one of the drawbacks of our study is its retrospective design for evaluating QOL. BT is currently under a nationwide prospective longitudinal evaluation for acute and late toxicity.

We found no statistically significant difference in overall global health after RP compared to BT, but data showed a trend for BT patients to score worse in the first year after operation and to be better for any later year of follow-up, compared to RP patients. When adjusted for follow-up length, age or pre-treatment PSA-level, no significant differences in patients' general QOL could be identified. Unfortunately, our sample size of patients is small. Further, we performed a retrospective cross-sectional study and did not prospectively evaluate the QOL, which would have been more precise as this would have given us a personal baseline for each patient before treatment and would have made significant changes in the QOL of each patient clearly visible. 
Table 1. Global health and functional scales after RP and BT

\begin{tabular}{|c|c|c|c|c|c|c|}
\hline & $\begin{array}{l}5-12 \text { months } \\
\mathrm{n}=21(12 / 9)\end{array}$ & $\begin{array}{l}13-24 \text { months } \\
\mathrm{n}=20(11 / 9)\end{array}$ & $\begin{array}{l}25-36 \text { months } \\
\mathrm{n}=14(8 / 6)\end{array}$ & $\begin{array}{l}37-53 \text { months } \\
\mathrm{n}=8(5 / 3)\end{array}$ & $\begin{array}{l}\mathrm{p} \text { within } \\
\text { groups }\end{array}$ & $\begin{array}{l}\mathrm{p} \text { between } \\
\text { groups }\end{array}$ \\
\hline \multicolumn{7}{|l|}{ Global health } \\
\hline Prostatectomy & $71.7 \pm 27.4$ & $78.1 \pm 24.0$ & $80.6 \pm 11.4$ & $77.8 \pm 9.6$ & NS & \\
\hline Brachytherapy & $58.3 \pm 35.4$ & $85.0 \pm 12.3$ & $87.5 \pm 7.0$ & $90.0 \pm 7.0$ & NS & \\
\hline Overall & $67.9 \pm 27.4$ & $81.9 \pm 18.1$ & $84.0 \pm 9.7$ & $85.4 \pm 9.7$ & & NS \\
\hline \multicolumn{7}{|c|}{ Cognitive functioning } \\
\hline Prostatectomy & $80.0 \pm 13.9$ & $75.0 \pm 30.9$ & $88.9 \pm 13.6^{*}$ & $88.9 \pm 19.2$ & NS & \\
\hline Brachytherapy & $33.3 \pm 23.6$ & $95.0 \pm 8.1$ & $97.2 \pm 6.8^{*}$ & $93.3 \pm 9.1$ & NS & \\
\hline Overall & $66.7 \pm 27.2$ & $86.1 \pm 23.0$ & $93.1 \pm 11.1^{*}$ & $91.7 \pm 12.6$ & & 0.029 \\
\hline \multicolumn{7}{|c|}{ Emotional functioning } \\
\hline Prostatectomy & $68.3 \pm 32.5$ & $74.0 \pm 37.6$ & $91.7 \pm 9.1$ & $88.9 \pm 12.7$ & NS & \\
\hline Brachytherapy & $54.2 \pm 41.2$ & $85.8 \pm 17.6$ & $93.1 \pm 11.1$ & $90.0 \pm 14.9$ & NS & \\
\hline Overall & $64.3 \pm 32.2$ & $80.6 \pm 28.0$ & $92.4 \pm 9.7$ & $89.6 \pm 13.2$ & & NS \\
\hline \multicolumn{7}{|c|}{ Physical functioning } \\
\hline Prostatectomy & $97.3 \pm 6.0$ & $90.8 \pm 23.4$ & $95.6 \pm 6.9$ & $97.8 \pm 3.8$ & NS & \\
\hline Brachytherapy & $76.7 \pm 33.0$ & $97.3 \pm 4.7$ & $98.9 \pm 2.7$ & $100.0 \pm 0.0$ & NS & \\
\hline Overall & $91.4 \pm 17.5$ & $94.4 \pm 15.7$ & $97.2 \pm 5.3$ & $99.2 \pm 2.4$ & & NS \\
\hline \multicolumn{7}{|l|}{ Role functioning } \\
\hline Prostatectomy & $80.0 \pm 27.4$ & $95.8 \pm 11.8$ & $97.2 \pm 6.8$ & $100.0 \pm 0.0$ & NS & \\
\hline Brachytherapy & $66.7 \pm 47.1$ & $95.0 \pm 11.2$ & $100.0 \pm 0.0$ & $100.0 \pm 0.0$ & NS & \\
\hline Overall & $76.2 \pm 30.2$ & $95.4 \pm 11.2$ & $98.6 \pm 4.8$ & $100.0 \pm 0.0$ & & NS \\
\hline \multicolumn{7}{|l|}{ Social functioning } \\
\hline Prostatectomy & $76.7 \pm 25.3$ & $81.3 \pm 25.9$ & $86.1 \pm 12.5$ & $77.8 \pm 38.5$ & NS & \\
\hline Brachytherapy & $58.3 \pm 35.4$ & $91.7 \pm 14.2$ & $91.7 \pm 13.9$ & $90.0 \pm 14.9$ & NS & \\
\hline Overall & $71.4 \pm 26.7$ & $87.0 \pm 20.3$ & $88.9 \pm 13.0$ & $85.4 \pm 24.3$ & & NS \\
\hline
\end{tabular}

Functional scales were similar after RP and BT, and again we found a similar pattern of BT patients scoring worse in the first year after operation and better thereafter. Symptom scales and items showed a significant change for patients treated with BT, with mainly gastrointestinal side effects reflecting the temporary toxicity of this technique and possibly also being a side effect of the administered tamsulosin medication.

Our findings are comparable with data in the recent literature (table 3). Davis et al. [11] compared RP, BT and $\mathrm{RT}$ in a cross-sectional study and found no difference in the overall QOL between BT and RP cohorts. Bacon et al. [12] reported a cross-sectional analysis comparing $\mathrm{RP}$, RT and BT. Compared with RP, RT was associated with significantly lower QOL scores, while no significant differences were reported between RP and BT. BT was associated with poorer bowel function and worse bowel complaints.
Interestingly, no investigator could find a clearly better general QOL after BT compared to the other treatment modalities, although some aspects were favourable for this technique. These findings are confirmed by our study.

Urinary morbidity has been reported to have a severe impact on QOL. In our study we found no significant difference in IPSS for BT patients compared to RP patients. The IPSS is designed to evaluate symptoms from benign prostatic hyperplasia and does not record incontinence, therefore the data from patients after RP have to be interpreted with care. We believe that the level of urinary toxicity after BT is reflected adequately by the IPSS. In the questionnaire recently released by the EORTC, the prostate module (PR-25) is designed to evaluate urinary symptoms including incontinence, and could therefore be better for evaluating the impact of different treatment modalities on urinary function for future studies.

In a prospective study, Fulmer et al. [17] evaluated voiding function after RP and BT with hormonal thera- 
Table 2. Symptom scales and single items after RP and BT

\begin{tabular}{|c|c|c|c|c|c|c|}
\hline & $\begin{array}{l}5-12 \text { months } \\
\mathrm{n}=21(12 / 9)\end{array}$ & $\begin{array}{l}13-24 \text { months } \\
\mathrm{n}=20(11 / 9)\end{array}$ & $\begin{array}{l}25-36 \text { months } \\
n=14(8 / 6)\end{array}$ & $\begin{array}{l}37-53 \text { months } \\
\mathrm{n}=8(5 / 3)\end{array}$ & $\begin{array}{l}\text { p within } \\
\text { groups }^{1}\end{array}$ & $\begin{array}{l}\mathrm{p} \text { between } \\
\text { groups }^{2}\end{array}$ \\
\hline \multicolumn{7}{|l|}{ Appetite } \\
\hline Prostatectomy & $0.0 \pm 0.0$ & $4.2 \pm 11.8$ & $0.0 \pm 0.0$ & $0.0 \pm 0.0$ & NS & \\
\hline Brachytherapy & $33.3 \pm 47.1$ & $0.0 \pm 0.0$ & $0.0 \pm 0.0$ & $0.0 \pm 0.0$ & 0.008 & \\
\hline Overall & $9.5 \pm 25.2$ & $1.9 \pm 7.9$ & $0.0 \pm 0.0$ & $0.0 \pm 0.0$ & & NS \\
\hline \multicolumn{7}{|l|}{ Constipation } \\
\hline Prostatectomy & $40.0 \pm 43.5$ & $12.5 \pm 17.3$ & $5.6 \pm 13.6$ & $11.1 \pm 19.2$ & NS & \\
\hline Brachytherapy & $33.3 \pm 47.1$ & $3.3 \pm 10.5$ & $0.0 \pm 0.0$ & $0.0 \pm 0.0$ & NS & \\
\hline Overall & $38.1 \pm 40.5$ & $7.4 \pm 14.3$ & $2.8 \pm 9.6$ & $4.2 \pm 11.8$ & & NS \\
\hline \multicolumn{7}{|l|}{ Diarrhoea } \\
\hline Prostatectomy & $20.0 \pm 18.3$ & $4.2 \pm 11.8^{*}$ & $16.7 \pm 27.9$ & $0.0 \pm 0.0$ & NS & \\
\hline Brachytherapy & $0.0 \pm 0.0$ & $13.3 \pm 17.2^{*}$ & $0.0 \pm 0.0$ & $6.7 \pm 14.9$ & 0.031 & \\
\hline Overall & $14.3 \pm 17.8$ & $9.3 \pm 15.4^{*}$ & $8.3 \pm 20.7$ & $4.2 \pm 11.8$ & & 0.009 \\
\hline \multicolumn{7}{|l|}{ Dyspnoea } \\
\hline Prostatectomy & $6.7 \pm 14.9$ & $8.3 \pm 15.4$ & $5.6 \pm 13.6^{*}$ & $0.0 \pm 0.0$ & NS & \\
\hline Brachytherapy & $33.3 \pm 47.1$ & $0.0 \pm 0.0$ & $0.0 \pm 0.0^{*}$ & $6.7 \pm 14.9$ & NS & \\
\hline Overall & $14.3 \pm 26.2$ & $3.7 \pm 10.8$ & $2.8 \pm 9.6^{*}$ & $4.2 \pm 11.8$ & & 0.005 \\
\hline \multicolumn{7}{|l|}{ Fatigue } \\
\hline Prostatectomy & $15.6 \pm 14.9$ & $19.4 \pm 29.5$ & $5.6 \pm 9.3$ & $0.0 \pm 0.0$ & NS & \\
\hline Brachytherapy & $44.4 \pm 62.9$ & $10.0 \pm 13.3$ & $4.6 \pm 7.4$ & $6.7 \pm 9.9$ & 0.031 & \\
\hline Overall & $23.8 \pm 31.7$ & $14.2 \pm 21.8$ & $5.1 \pm 8.0$ & $4.2 \pm 8.3$ & & NS \\
\hline \multicolumn{7}{|c|}{ Financial difficulties } \\
\hline Prostatectomy & $0.0 \pm 0.0$ & $20.8 \pm 30.5$ & $5.6 \pm 13.6$ & $0.0 \pm 0.0$ & NS & \\
\hline Brachytherapy & $50.0 \pm 23.6$ & $10.0 \pm 22.5$ & $0.0 \pm 0.0$ & $20.0 \pm 44.7$ & NS & \\
\hline Overall & $14.3 \pm 26.2$ & $14.8 \pm 26.1$ & $2.8 \pm 9.6$ & $12.5 \pm 35.4$ & & NS \\
\hline \multicolumn{7}{|c|}{ Nausea and vomiting } \\
\hline Prostatectomy & $0.0 \pm 0.0^{*}$ & $6.3 \pm 17.7$ & $0.0 \pm 0.0$ & $0.0 \pm 0.0$ & NS & \\
\hline Brachytherapy & $8.3 \pm 11.8^{*}$ & $0.0 \pm 0.0$ & $2.8 \pm 6.8$ & $0.0 \pm 0.0$ & 0.037 & \\
\hline Overall & $2.4 \pm 6.3^{*}$ & $2.8 \pm 11.8$ & $1.4 \pm 4.8$ & $0.0 \pm 0.0$ & & 0.026 \\
\hline \multicolumn{7}{|l|}{ Pain } \\
\hline Prostatectomy & $16.7 \pm 23.6$ & $8.3 \pm 23.6$ & $0.0 \pm 0.0$ & $0.0 \pm 0.0$ & NS & \\
\hline Brachytherapy & $33.3 \pm 47.1$ & $3.3 \pm 7.0$ & $8.3 \pm 13.9$ & $0.0 \pm 0.0$ & NS & \\
\hline Overall & $21.4 \pm 28.4$ & $5.6 \pm 16.2$ & $4.2 \pm 10.4$ & $0.0 \pm 0.0$ & & NS \\
\hline \multicolumn{7}{|l|}{ Insomnia } \\
\hline Prostatectomy & $13.3 \pm 18.3$ & $20.8 \pm 30.5$ & $5.6 \pm 13.6$ & $0.0 \pm 0.0$ & NS & \\
\hline Brachytherapy & $16.7 \pm 23.6$ & $13.3 \pm 17.2$ & $5.6 \pm 13.6$ & $6.7 \pm 14.9$ & NS & \\
\hline Overall & $14.3 \pm 17.8$ & $16.7 \pm 23.6$ & $5.6 \pm 13.0$ & $4.2 \pm 11.8$ & & NS \\
\hline
\end{tabular}

All values are means $\pm \mathrm{SD}$.

p values within groups according to the Kruskal-Wallis test and between groups according to the Mann-Whitney U test.

* Significant difference between treatment groups.

py. They found a significant increase in total American Urological Association Symptom Score after BT, and only after RP did patients return to near-baseline scores again. For urinary continence $42 \%$ of patients after RP and $75 \%$ after BT had returned to baseline at 12 months. Miller et al. [16] compared long-term outcome after RP, RT and BT. They found a significant improvement in irritative and obstructive symptoms a median of 6.2 years after BT, whereas urinary incontinence QOL worsened. In patients after RP, no QOL changes over this time period were observed. Comparing RP and BT $[10-12,14]$, most authors found urinary symptoms or bother to be worse after BT, but continence was generally better. Concerning QOL, it remains controversial whether irritative and obstructive voiding symptoms or incontinence is of more concern for the individual patient. According to our results, the impact on urinary function and general QOL seems to be similar for both treatment modalities. 
Table 3. Recent literature on comparison of QOL after treatment for localized prostate cancer

\begin{tabular}{|c|c|c|c|c|c|c|c|}
\hline \multirow[t]{2}{*}{ Authors } & \multirow[t]{2}{*}{ Year } & \multicolumn{3}{|c|}{ Number per method } & \multirow{2}{*}{$\begin{array}{l}\text { Follow- } \\
\text { up }\end{array}$} & \multirow[t]{2}{*}{ Type of study questionnaire } & \multirow[t]{2}{*}{ Results } \\
\hline & & $\mathrm{RP}$ & $\mathrm{BT}$ & RT & & & \\
\hline $\begin{array}{l}\text { Miller } \\
\text { et al. [16] }\end{array}$ & 2005 & \multicolumn{3}{|c|}{ general 709} & 6.2 years & $\begin{array}{l}\text { Prospective longitudinal } \\
\text { RAND SF-12 } \\
\text { EPIC- } 26\end{array}$ & $\begin{array}{l}\text { General: no differences } \\
\text { Urinary: BT improvement irritative-obstructive, } \\
\text { BT/RT worsened incontinence, RP no changes } \\
\text { Sexual: RT worsened, RP no changes }\end{array}$ \\
\hline $\begin{array}{l}\text { Borchers } \\
\text { et al. [8] }\end{array}$ & 2004 & $80^{1}$ & 52 & - & 1 year & $\begin{array}{l}\text { Prospective longitudinal } \\
\text { EORTC QLQ C-30 } \\
\text { ICS male incontinence } \\
\text { Kelly }\end{array}$ & $\begin{array}{l}\text { General: no differences } \\
\text { Urinary: RP most bothersome incontinence } \\
\text { Sexual: RP worse, BT only minor change }\end{array}$ \\
\hline $\begin{array}{l}\text { Bradley } \\
\text { et al. [14] }\end{array}$ & 2004 & 60 & $154^{2}$ & - & $\begin{array}{l}19-30 \\
\text { months }\end{array}$ & $\begin{array}{l}\text { Cross-sectional } \\
\text { FACT-G, AUA-SS } \\
\text { Brief sexual function inventory }\end{array}$ & $\begin{array}{l}\text { General: no differences } \\
\text { Urinary: BT worse symptoms, BT better continence } \\
\text { Sexual: BT initially better function, does not persist over time }\end{array}$ \\
\hline $\begin{array}{l}\text { Downs } \\
\text { et al. [15] }\end{array}$ & 2003 & 327 & 92 & - & $\begin{array}{l}18-21 \\
\text { months }\end{array}$ & $\begin{array}{l}\text { Prospective longitudinal } \\
\text { RAND SF-36 } \\
\text { UCLA PCI }\end{array}$ & $\begin{array}{l}\text { General: no differences } \\
\text { Urinary: BT better function, bother no difference } \\
\text { Sexual: BT and RP decreases in function }\end{array}$ \\
\hline $\begin{array}{l}\text { Wei } \\
\text { et al. [13] }\end{array}$ & 2002 & 896 & 114 & $203^{3}$ & n.a. & $\begin{array}{l}\text { Cross-sectional } \\
\text { RAND SF-36 } \\
\text { FACT-G/FACT-P, EPIC }\end{array}$ & $\begin{array}{l}\text { General: all worse compared to healthy volunteers } \\
\text { Urinary: RP and BT worse } \\
\text { Sexual: BT worse }\end{array}$ \\
\hline $\begin{array}{l}\text { Bacon } \\
\text { et al. [12] }\end{array}$ & 2001 & 421 & 69 & $221^{4}$ & $\begin{array}{l}13-32 \\
\text { months }\end{array}$ & $\begin{array}{l}\text { Cross-sectional } \\
\text { CARES SF } \\
\text { RAND SF-36 }\end{array}$ & $\begin{array}{l}\text { General: } B T \text { and } R P \text { no differences, } R T \text { worse } \\
\text { Urinary: BT better function and worse bother than RP } \\
\text { Sexual: BT better function, less bother than RP }\end{array}$ \\
\hline $\begin{array}{l}\text { Davis } \\
\text { et al. [11] }\end{array}$ & 2001 & 269 & 142 & 222 & $\begin{array}{l}22-38 \\
\text { months }\end{array}$ & $\begin{array}{l}\text { Cross-sectional } \\
\text { RAND SF-36 } \\
\text { UCLA PCI }\end{array}$ & $\begin{array}{l}\text { General: } B T \text { and } R P \text { no differences } \\
\text { Urinary: RP worse } \\
\text { Sexual: RP worse }\end{array}$ \\
\hline $\begin{array}{l}\text { Lee } \\
\text { et al. [10] }\end{array}$ & 2001 & 23 & 44 & 23 & 1 year & $\begin{array}{l}\text { Prospective longitudinal } \\
\text { FACT-G/FACT-P } \\
\text { IPSS }\end{array}$ & $\begin{array}{l}\text { General: } B T \text { and } R P / R T \text { no differences } \\
\text { Urinary: BT worse symptoms } \\
\text { Sexual: n.a. }\end{array}$ \\
\hline $\begin{array}{l}\text { Krupski } \\
\text { [9] }\end{array}$ & 2000 & 27 & $111^{2}$ & - & 1 year & $\begin{array}{l}\text { Cross-sectional } \\
\text { FACT-G, IPSS } \\
\text { Urinary function questionnaire } \\
\text { for men } \\
\text { Brief sexual function inventory }\end{array}$ & $\begin{array}{l}\text { General: BT monotherapy and RP no difference } \\
\text { Improvement over time; BTC worse, decline over time } \\
\text { Urinary: RP lowest IPSS, better irritative and obstructive } \\
\text { symptoms } \\
\text { Sexual: BTM and RP improvement over time; BTC decline } \\
\text { over time }\end{array}$ \\
\hline
\end{tabular}

EPIC = Expanded Prostate Cancer Index Composite; ICS = International Continence Society; FACT-G/P = Functional Assessment of Cancer Therapy General/Prostate; AUA-SS = American Urological Association Symptom Score; UCLA PCI = UCLA Prostate Cancer Index; EPIC = Expanded Prostate Cancer Index Composite; CARES SF = Cancer Rehabilitation Evaluation System Short Form; n.a. = not available.

${ }^{1}$ Perineal radical prostatectomy, 38 with nerve sparing compared to 42 without nerve sparing.

${ }^{2}$ Comparing BT monotherapy and BT combined with external beam radiotherapy (BTC).

${ }^{3}$ All groups compared to matched healthy volunteers.

${ }^{4}$ Compared to hormonal therapy $(\mathrm{n}=33)$ and watchful waiting $(\mathrm{n}=31)$.

QOL is becoming an important issue for our well-informed patients with prostate cancer when evaluating the different treatment options together with their physician. Gwede et al. [4] could show that patients who received BT chose this treatment because of QOL considerations, whereas 'cure' and complete removal of the tumour was the main motivation for patients selecting RP.
Interestingly, BT and RP have similar QOL outcome on intermediate-term follow-up. In the first year after operation there is a trend in favour of RP, but for the following years scores are better for BT.

We have to admit that our study has a selection bias. Patients receiving BT were younger with more favourable tumour characteristics than those undergoing RP. But this reflects our strict policy of only performing BT as 
monotherapy without external beam radiotherapy or hormonal manipulation in low- and intermediate-risk patients. As no information on biochemical recurrence and following adjuvant treatment was collected, the impact of this on QOL cannot be estimated, but it could represent a bias of the study. When patients were adjusted for age and PSA value, no significant difference in outcome of any treatment modality could be found. Some QOL symptom scales such as nausea, vomiting and dyspnoea are presumably not related to the intervention but to the individual patient's comorbidities. Further, patients' comorbidities were not recorded, and they could bias our study as they influence QOL.

Of course, prospective randomized trials would be desirable for a non-biased evaluation. However, as most patients are well-informed, they wish to decide themselves which treatment to choose and want their physician to provide them with the relevant information. Therefore, it is important for any physician counselling patients with localized prostate cancer to know about health-related QOL data for the different treatment modalities.

\section{Conclusions}

Patients treated with BT have worse global health, functional scales and symptom scales in the first year after treatment and score better than RP patients in most domains thereafter. Gastrointestinal symptoms are temporarily more prominent after BT compared to RP.

Further studies are needed to prospectively evaluate long-term QOL for the treatment of localized prostate cancer.

\section{References}

1 Aus G, Abbou CC, Bolla M, Heidenreich A, Schmid HP, van Poppel H, Wolff J, Zattoni F: EAU guidelines on prostate cancer. Eur Urol 2005;48:546-551.

$\checkmark 2$ Penson DF, Litwin MS, Aaronson NK: Health related quality of life in men with prostate cancer. J Urol 2003;169:1653-1661.

- 3 Helgason AR, Adolfsson J, Dickman P, Fredrikson M, Arver S, Steineck G: Waning sexual function: the most important diseasespecific distress for patients with prostate cancer. Br J Cancer 1996;73:1417-1421.

4 Gwede CK, Pow-Sang J, Seigne J, Heysek R, Helal M, Shade K, Cantor A, Jacobsen PB: Treatment decision-making strategies and influences in patients with localized prostate carcinoma. Cancer 2005;104:1381-1390.

5 Walsh PC: Anatomic radical prostatectomy: evolution of the surgical technique. J Urol $1998 ; 160: 2418-2424$.

-6 Nag S, Beyer D, Friedland J, Grimm P, Nath R: American Brachytherapy Society (ABS) recommendations for transperineal permanent brachytherapy of prostate cancer. Int J Radiat Oncol Biol Phys 1999;44:789-799.

7 Hall JD, Boyd JC, Lippert MC, Theodorescu D: Why patients choose prostatectomy or brachytherapy for localized prostate cancer: results of a descriptive survey. Urology 2003; 61:402-407.
Borchers $\mathrm{H}$, Kirschner-Hermanns R, Brehmer B, Tietze L, Reineke T, Pinkawa M, Eble MJ, Jakse G: Permanent 125I-seed brachytherapy or radical prostatectomy: a prospective comparison considering oncological and quality of life results. BJU Int 2004;94: 805-811.

9 Krupski T, Petroni GR, Bissonette EA, Theodorescu D: Quality-of-life comparison of radical prostatectomy and interstitial brachytherapy in the treatment of clinically localized prostate cancer. Urology 2000;55: 736-742.

10 Lee WR, Hall MC, McQuellon RP, Case LD, McCullough DL: A prospective quality-oflife study in men with clinically localized prostate carcinoma treated with radical prostatectomy, external beam radiotherapy, or interstitial brachytherapy. Int J Radiat Oncol Biol Phys 2001;51:614-623.

11 Davis JW, Kuban DA, Lynch DF, Schellhammer PF: Quality of life after treatment for localized prostate cancer: differences based on treatment modality. J Urol 2001;166:947952.

12 Bacon CG, Giovannucci E, Testa M, Kawachi I: The impact of cancer treatment on quality of life outcomes for patients with localized prostate cancer. J Urol 2001;166:1804-1810.

$\checkmark 13$ Wei JT, Dunn RL, Sandler HM, McLaughlin PW, Montie JE, Litwin MS, Nyquist L, Sanda MG: Comprehensive comparison of healthrelated quality of life after contemporary therapies for localized prostate cancer. J Clin Oncol 2002;20:557-566.
14 Bradley EB, Bissonette EA, Theodorescu D: Determinants of long-term quality of life and voiding function of patients treated with radical prostatectomy or permanent brachytherapy for prostate cancer. BJU Int 2004;94: 1003-1009.

15 Downs TM, Sadetsky N, Pasta DJ, Grossfeld GD, Kane CJ, Mehta SS, Carroll PR, Lubeck DP: Health related quality of life patterns in patients treated with interstitial prostate brachytherapy for localized prostate cancer: data from CaPSURE. J Urol 2003;170:18221827.

16 Miller DC, Sanda MG, Dunn RL, Montie JE, Pimentel H, Sandler HM, Mc Laughlin JP, Wei JT: Long-term outcomes among localized prostate cancer survivors: healthrelated quality-of-life changes after radical prostatectomy, external radiation, and brachytherapy. J Clin Oncol 2005;23:27722780.

17 Fulmer BR, Bissonette EA, Petroni GR, Theodorescu D: Prospective assessment of voiding and sexual function after treatment for localized prostate carcinoma: comparison of radical prostatectomy to hormonobrachytherapy with and without external beam radiotherapy. Cancer 2001;91:2046-2055. 